\title{
AS BRINCADEIRAS FOLCLÓRICAS NA EDUCAÇÃO FÍSICA INFANTIL: INFLUÊNCIAS NO DESENVOLVIMENTO AFETIVO-SOCIAL
}

Elise Helena de Morais Batista

Andréa Rodrigues de Amorim

\section{Resumo}

Este estudo busca analisar a importância do resgate cultural realizado através das brincadeiras folclóricas para o desenvolvimento afetivo-social de pré-escolares de 4 a 7 anos, segundo a visão docente. Foi aplicado um questionário aberto contendo quatro perguntas, a dez professoras de Educação Infantil, de duas prefeituras distintas. A análise qualitativa dos dados demonstrou que a vivência das brincadeiras folclóricas favorece o desenvolvimento de atitudes como: solidariedade, respeito mútuo, interação, socialização, cooperação, respeito a regras, construção de limites e elevação da auto-estima. Foi possível concluir que essas brincadeiras constituem-se uma prática rica e significativa para a Educação Física Infantil, e por essa razão devem estar presentes no currículo escolar durante todo ano letivo.

\section{Palavras-Chave}

Brincadeiras folclóricas; Resgate cultural; Desenvolvimento afetivo-social; Educação Física infantil.

\section{THE FOLKLORIC PLAY IN INFANT PHYSICAL EDUCATION: INFLUENCES IN SOCIAL} AFFECTIVE DEVELOPMENT

Elise Helena de Morais Batista

Andréa Rodrigues de Amorim

\begin{abstract}
In this article we present an analysis the importance of the folclorics tricks in the Infantile Education in the affective-social development of preschool of 4 the 7 years, according to teaching vision. An open questionnaire was applied contends four questions, the ten teachers of Infantile Education, two distinct city halls. The qualitative analysis of the data demonstrated that the experience of the folclorics tricks favors the development of attitudes as: solidarity, mutual respect, interaction, socialization, cooperation, respect the rules, construction of limits and rise of self-esteem. It was possible to conclude that these tricks consist one practical rich and significant one for the Infantile Physical Education, and therefore they must be gifts in the pertaining to school resume during all school year.
\end{abstract}

\section{Key-Words}

Folclorics Tricks; Cultural rescue; Affective-social development; Infantile Physical Education 


\section{INTRODUÇÃO}

A Educação Física Infantil, através do brincar, tem a oportunidade de proporcionar aos alunos vivências corporais diversas, contribuindo de forma lúdica para o desenvolvimento global dos alunos. As brincadeiras folclóricas surgem como uma estratégia de grande destaque por sua função de resgate cultural.

Vivemos atualmente em uma sociedade em que as crianças, em grande parte, já não vivenciam brincadeiras como vivenciavam em outras épocas do século XX, devido, dentre várias coisas, ao aumento da tecnologia e da globalização, que leva as pessoas a estarem cada vez mais dentro de suas próprias casas. Como afirma Soler (2003, p. 135) "Hoje as crianças já não podem brincar livremente pelas ruas, pois dois motivos as impedem: o crescente desenvolvimento das cidades e a escalada da violência".

Uma das conseqüências desse processo é que as práticas e valores culturais estão sendo deixados no esquecimento, pela falta de locais para praticá-las, como pela vida agitada da sociedade. A Educação Física Escolar pode ajudar no processo de resgate e perpetuação da cultura, pois "a própria dinâmica escolar passou a ser considerada como prática cultural" (DAOLIO, 2003, p. S 34).

O interesse de estudar a importância das brincadeiras folclóricas na Educação Infantil como um meio de preservar e resgatar a cultura dos alunos, pois, como diz Freire (1997, p. 13): "Negar a cultura Infantil é, no mínimo, mais uma das cegueiras do sistema escolar".

\section{OBJETIVO}

O presente estudo tem como objetivo revelar a importância do respeito à cultura corporal de alunos da Educação Infantil, tendo como estratégia a prática das brincadeiras folclóricas, e estudar as contribuições destas no desenvolvimento afetivo- social de crianças de 4 a 7 anos, em duas prefeituras distintas. Faremos isso partindo do pressuposto que o ser humano não desenvolve seus aspectos afetivos, sociais, cognitivos e motores separadamente, mas sim que estes relacionam-se.

Espera-se com esta leitura contribuir para um olhar mais reflexivo sobre a importância do resgate das brincadeiras folclóricas na Educação Física Infantil. 


\section{O DESENVOLVIMENTO AFETIVO E SOCIAL EM CRIANÇAS DE 4 A 7 ANOS}

A base para a análise do desenvolvimento infantil, com enfoque nos aspectos afetivos e sociais, se sustentará na teoria de Jean Piaget (1977). Vale ressaltar que as crianças na faixa etária deste estudo encontram-se no estágio pré-operatório, e a partir dos seis anos aproximadamente entram na fase de transição para o estágio operatório-concreto. Cada criança é um ser único e por esta razão deve ser respeitado seu ritmo próprio de desenvolvimento.

\section{DESENVOLVIMENTO SOCIAL NAS CRIANÇAS DE 4 A 7 ANOS}

A partir dos dois anos, com a constituição da inteligência representativa e aquisição da linguagem, surgem novas relações sociais que enriquecem e transformam o pensamento da criança. O pensamento da criança de 2 a 7 anos é intuitivo, pois deixa-se levar apenas por aquilo que consegue observar. O pensamento intuitivo caracteriza-se pelo egocentrismo, uma vez que a criança não tem consciência de sua subjetividade. O egocentrismo ocorre a nível intelectual, afetivo e social. Desta maneira, a criança nesta idade não consegue ainda considerar o ponto de vista dos outros, somente o próprio:

Ela é incapaz de aceitar pontos de vista diferentes do seu, assim como tem dificuldades em aprender regras sociais ou de jogos, compartilhar suas coisas ou desempenhar tarefas em cooperação com outras pessoas. Não consegue, em suas relações pessoais, dissociar seus interesses, desejos e necessidades dos interesses, desejos e necessidades de outras pessoas. Há identificação e mesmo confusão entre ela e os outros (BRASIL, 1995, p. 54).

Por meio de jogos de grupo e brincadeiras coletivas pode-se observar uma mudança significativa nas atividades sociais da criança. Geralmente, as crianças de quatro a seis anos costumam seguir o exemplo dos mais velhos, seguindo algumas regras que conhece, sem coordená-las com outras regras de crianças da mesma idade. Já a partir dos sete anos, as crianças passam a preocupar-se no fato de que as regras devem ser iguais para todos, observando-as e controlando-as (ASSIS, O., 2003). Segundo Brasil (1995), as crianças entre 6 e 7 anos já conseguem escutar o que seus amigos têm a dizer e aceitar opiniões diferentes. Quando a criança já tem a capacidade de coordenar pontos de vista diferentes, ela já apresenta mais condições para a aprendizagem de regras, fundamental para seu desenvolvimento social.

A heteronomia é um importante aspecto da criança pré-operatória. Na heteronomia, a criança se deixa governar pelos outros, através da existência de um respeito unilateral entre criança e adulto. Assim, a criança apenas obedece a regras, independente do que essas impõem. O cumprimento de regras torna-se 
muitas vezes algo mecânico, e não necessariamente uma conscientização da importância desta por parte da criança. O convívio no ambiente familiar e escolar contribui de maneira direta com o desenvolvimento social da criança, de maneira a buscar a superação do egocentrismo social e intelectual desta. O processo de socialização da criança é progressivo, conforme vai conhecendo e convivendo com o espaço social que a cerca e com seus padrões e regras de comportamento.

\section{DESENVOLVIMENTO AFETIVO NAS CRIANÇAS DE 4 A 7 ANOS}

$\mathrm{O}$ afeto inclui sentimentos, interesses, desejos tendências, valores e emoções em geral. Exerce papel fundamental nas correlações psicossomáticas básicas, influenciando também: percepção, memória, pensamento e ações (KRUEGER, 2003).

Para Piaget apud Assis (2003), a afetividade engendra o motor de todo e qualquer conhecimento. Para ele, a relação entre afetividade e inteligência é tão estreita que não há ação puramente intelectual, assim como não há atos puramente afetivos, sendo os dois aspectos indissociáveis em uma mesma ação.

No estágio pré-operatório, os afetos são intuitivos, regulados pelos interesses ou valores momentâneos. Segundo Piaget, na esfera da afetividade, o equilíbrio dos sentimentos aumenta conforme a idade, assim como nas relações sociais.

O aparecimento das simpatias e antipatias se torna possível a partir do aparecimento da linguagem, e está ligada a valorização dos outros (ASSIS, O. 2003). O sentimento de simpatia costuma desenvolver-se pelas pessoas que respondem aos interesses que as crianças valorizam. Além disso, costuma existir uma valorização recíproca e apreciação mútua entre as pessoas com sentimentos de simpatia, assim como a existência de valores em comum entre os mesmos. Por outro lado, os sentimentos de antipatia dão-se justamente quando as pessoas envolvidas não têm escala de valores em comum, em trocas afetivas deficitárias e ausência de enriquecimento mútuo.

Segundo Assis (2003), as relações deficitárias, como da antipatia, podem e devem ser minimizadas através de situações favoráveis, sendo uma delas os jogos de cooperação, pois, enquanto as crianças brincam juntas em grupos de acordo com seus interesses, têm a oportunidade de entenderem-se e manterem trocas afetivas positivas. Já os jogos competitivos podem provocar relações deficitárias que geram antipatia, e por isso devem ser escolhidas e praticadas com cuidado pelos professores, para que não prejudiquem o relacionamento dos alunos. 
Nesta idade também ocorre o aparecimento de sentimentos de inferioridade e superioridade que segundo Piaget apud Assis (2003), estão ligados à auto-valorização, troca afetiva consigo mesmo em contraposição à troca com o outro.

Encontra-se no estágio sensório-motor as raízes deste tipo de sentimento, advindas das experiências de fracasso ou sucesso que ocorreram nesta fase. Enquanto as situações de sucesso geram confiança, as situações de fracasso angustiam e diminuem a confiança. Na faixa etária em questão, é essencial a existência de um bom relacionamento afetivo entre professor e alunos, de maneira a existir no meio escolar um clima propício para a aprendizagem.

\section{AS BRANCADEIRAS FOLCLÓRICAS NA EDUCAÇÃO INFANTIL}

O brincar traz como característica marcante seu aspecto lúdico, constituindo-se uma manifestação do ser humano em qualquer idade. Para as crianças, constitui-se uma de suas atividades mais importantes, considerado inclusive por muito autores como sendo o "trabalho da criança" (LIMA, 1992).

Segundo o Referencial Curricular Nacional de Educação Infantil - RCNEI -(BRASIL, 1998a, p. 50), o brincar deve: "se constituir em atividade permanente e sua constância dependerá dos interesses que as crianças apresentam nas diferentes faixas etárias. "

Partindo-se da importância do brincar, percebemos que na Educação Infantil esta prática torna-se de grande importância para o desenvolvimento global das crianças. Segundo Piaget (1977), é no período préoperatório que as crianças têm sua maior capacidade de expressão simbólica, o que pode e deve ser ricamente explorado pelo professor através das brincadeiras.

Quais seriam as brincadeiras mais significativas para as crianças? A literatura da área sugere aquelas que levem em conta as vivências culturais do grupo, por duas principais razões que podemos citar aqui: a- As vivências dos aspectos culturais serão mais significativas para as crianças (respeito à cultura corporal do aluno), isso porque para elas é mágico descobrir que, as brincadeiras que estão realizando hoje, seus pais e avós realizavam muito tempo atrás, isso claro, se as crianças tiverem consciência deste fato, o que pode ocorrer através de pesquisas com as famílias, com idéias trazidas pelas crianças, deixando sempre com que a criança participe do planejamento das brincadeiras de maneira ativa e direta. b- Haverá um resgate de brincadeiras de cunho popular que, com o passar do tempo e o novo estilo de vida da sociedade, estão sendo deixadas no esquecimento. Muitas crianças hoje em dia não sabem o 
que são brincadeiras de rua, pois a maior parte do tempo passam dentro de suas próprias casas, e por isso a escola torna-se um meio para que esta cultura não venha perder-se através do tempo. Como Soler (2003, p. 140) afirma: "Acredito ser necessária uma verdadeira cruzada em favor de um resgate dos jogos da cultura popular, pois eles estão em extinção ".

A tradição das brincadeiras folclóricas tem ultrapassado gerações e gerações, espalhando-se por diferentes culturas e países. Concordamos com Ramos (2002), que diz:

Há uma infinidade de jogos e brincadeiras que ultrapassaram o tempo e permanecem vivos na memória de todos nós. As brincadeiras de antigamente trazem, em sua bagagem cultural, suas técnicas e regras, que são transmitidas de geração a geração pelos pais e avós. Junto vem o resgate da convivência, da ternura, dos momentos felizes, de sua história através dos tempos (RAMOS, 2002,)

Esse é o enfoque que observamos no resgate das brincadeiras folclóricas que, além da magia existente nelas e da diversão que proporcionam, trazem uma contribuição afetiva, repleta de significados para aqueles que as praticam, praticaram, assim como para aqueles que as estão ensinando para novas gerações.

Segundo Gallardo (2003), os jogos e as brincadeiras são parte fundamental da cultura corporal, e através delas nos apropriamos de diferentes manifestações culturais da nossa cultura de origem de forma lúdica, que integram nossa personalidade e identidade nacional. Será que a escola tem realizado o seu papel de contribuir para o resgate das brincadeiras folclóricas, utilizando-as como fonte de conhecimentos?

O que percebemos é que muitas vezes a escola não tem cumprido este papel, deixando a bagagem cultural que a criança carrega no "portão da escola" (Soler, 2003). Podemos observar o mesmo em muitas aulas de Educação Física Infantil. A escola, de maneira geral, deve ensinar novos conteúdos sem esquecer-se dos que a criança já possui, relacionando-os na busca de novos conhecimentos, em vivências corporais enriquecedoras.

O RCNEI (BRASIL, 1998b) fala sobre a importância destas brincadeiras, dizendo que devem estar relacionadas ao mundo social e natural dos alunos. Aconselha aos professores ensinar jogos e brincadeiras de outras épocas, propondo pesquisas com a família e comunidade, também através de livros e revistas, falando sobre as regras das brincadeiras em outros tempos, observando as mudanças que ocorreram, pois esta prática se torna interessante para as crianças. O professor deve estar junto com as crianças 
ajudando-as a combinar e cumprir regras, e a desenvolverem atitudes de respeito e cooperação que, além de tão necessárias para as crianças pré-escolares, tornam-se importantes para desenvolvimento de habilidades desportivas que estas venham a desenvolver mais tarde.

A conscientização por parte dos professores de Educação Física sobre a importância das brincadeiras folclóricas para o desenvolvimento global e preservação

da cultura de seu aluno é de grande importância, pois o professor assume papel fundamental nesse processo.

O professor deve propor brincadeiras desafiadoras, nas quais os alunos possam participar ativamente do começo ao fim, perpetuando a cultura infantil e favorecendo o prazer de brincar àqueles que têm na brincadeira sua maior especialidade!

\section{METODOLOGIA}

A metodologia aplicada no estudo consistiu em quatro etapas:

1. Pesquisa bibliográfica: Teve como objetivo o levantamento de referencial teórico para embasamento da pesquisa.

2. Elaboração do questionário: Foi elaborado um questionário aberto com quatro perguntas. Com o intuito de validá-lo, o mesmo foi analisado por profissionais da Educação: Docentes da faculdade, coordenadora e diretora pedagógica de Educação Infantil. A seguir, as perguntas na íntegra:

2.1-Qual a sua opinião sobre a prática de brincadeiras folclóricas durante um ano letivo com seus alunos?

2.2-Os alunos contribuem com idéias na realização do planejamento das brincadeiras? Como isso ocorre?

2.3-Ao trabalhar as brincadeiras folclóricas, você acredita que possa provocar mudanças de atitudes e valores dos alunos em seu meio social? Como?

2.4-Você consegue perceber alguma contribuição das brincadeiras folclóricas no desenvolvimento de outros aspectos (sociais, afetivos e cognitivos) em seus alunos, além do aspecto motor? Justifique.

3. Aplicação do questionário: Duas escolas de diferentes prefeituras participaram da pesquisa. O critério de escolha das escolas foi o número de salas com a mesma faixa etária, de 4 a 7 anos. O estudo foi apresentado às respectivas diretoras da escola e às professoras, que após concordarem

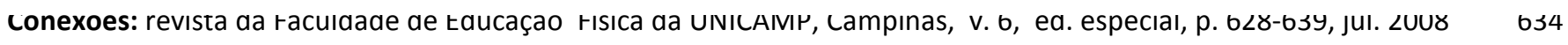
ISSN: $1983-903$ 
assinaram o Termo de Consentimento. Cinco professoras de cada escola responderam as perguntas de forma dissertativa. Em seguida as respostas foram recolhidas para análise.

3. Análise do questionário: As respostas foram analisadas qualitativamente, segundo o método "Análise de Conteúdo" de Bardin (1987), constituída por três etapas: a-Pré-análise, b- Descrição Analítica, c- Interpretação referencial.

\section{RESULTADOS}

As professoras, de maneira geral, atribuíram importância e significados diferentes que a prática das brincadeiras folclóricas trazem aos alunos. Entre as respostas, o que mais foi observado é o fato das brincadeiras folclóricas contribuírem para o resgate cultural, perpetuando brincadeiras que muitas vezes estão sendo deixadas no esquecimento pela sociedade atual: "Acho muito importante a prática dessas brincadeiras durante o ano, pois assim oportunizamos o cultivo das tradições folclóricas, não deixando morrer brincadeiras antigas" (Prof 10). Segundo as professoras, a realização destas atividades além de caracterizar uma cultura, ajuda a afirmar a identidade cultural da criança, aproximando práticas culturais familiares e comunitárias: "Proporciona uma aproximação da cultura trazida do meio familiar e comunitário de cada criança " (Prof 9).

As professoras também pontuaram aspectos sociais e afetivos, como: formação de valores, integração, contato físico com os colegas e divertimento proporcionado por esta vivência: "A prática de brincadeiras folclóricas durante o ano letivo é importante no processo de integração entre os alunos [...], garante a continuidade e a permanência de valores sócio-culturais na sociedade" (Prof 6).

Outro aspecto importante ressaltado por duas professoras foi o fato dos alunos tornarem-se mais interessados na aula quando as brincadeiras folclóricas são executadas: "Acredito ser muito enriquecedor, pois a aula fica mais dinâmica e os alunos mais interessados" (Prof 4). Sobre isto, podemos pontuar sua importância no processo de aprendizagem, pois, segundo Assis, O, (2003, p. 180): "O rendimento das crianças no trabalho escolar é bem melhor quando leva em conta seus interesses e quando correspondem às suas necessidades".

Sobre aspecto social, as brincadeiras folclóricas contribuem, segundo as professoras, para o desenvolvimento da socialização, através da conquista de valores sociais diversos, tais como: esperar a sua vez (para brincar, para falar); cooperar; respeitar os outros; cumprir regras combinadas; auxiliar os 
colegas; conviver em grupo; interar-se com outras crianças, adultos e professor, favorecendo uma aproximação entre todos.

Através desta aproximação, os alunos estarão aumentando sua afetividade. O aspecto afetivo, segundo as professoras, é desenvolvido através das brincadeiras folclóricas, pois, através delas os alunos podem: expressar sentimentos e emoções (em suas casas, com suas famílias, e na escola); lidar com possíveis frustrações; controlar impulsos; valorizar suas conquistas (contribuindo para sua auto-estima); desenvolver sua autonomia, através da escolha das brincadeiras a realizar; explorar sua criatividade; superar dificuldades; avaliar seu desempenho.

Se a relação afetiva entre as crianças melhora, é possível dizer que as brincadeiras folclóricas contribuem também para o surgimento de simpatias entre as crianças, amenizando os sentimentos de antipatia existentes (ASSIS, 2003).

Ao serem questionadas sobre a mudança de atitudes e valores que as brincadeiras folclóricas podem provocar nos alunos e em seu meio social, vários pontos foram levantados pelas professoras: cooperação, interação, solidariedade, respeito mútuo, valorização de regras e limites, melhora do convívio social e ambiente socializador.

Sobre os jogos eletrônicos, as brincadeiras folclóricas contribuem para que as crianças tenham vivências mais saudáveis e sadias, proporcionando um divertimento que não necessita de brinquedos comprados, nem um consumo desenfreado dos mesmos.

As brincadeiras folclóricas foram citadas como importantes também por não apresentarem violência tão presente na sociedade atual. Assim, o trabalho com a solidariedade e respeito pode se mais vivenciado. Proporcionar situações para que as crianças reflitam sobre suas vivências é o ponto importante do trabalhado realizado com as brincadeiras folclóricas, de maneira a contribuir para seu desenvolvimento afetivo e social: "As brincadeiras folclóricas proporcionam um pleno desenvolvimento nos alunos, permitindo a formação de conceitos, valores e atitudes, nos aspectos social, afetivo e cognitivo" (Prof 2).Muito pode ser discutido acerca da importância das brincadeiras folclóricas na Educação Física Infantil. Segundo as professoras entrevistadas, esta é uma prática que pode enriquecer as aulas e ajudar no desenvolvimento global dos alunos. 
Esse estudo é relevante para a Educação Física, pois atesta a importância do brincar para o desenvolvimento infantil. Por essa razão, o ideal seria que os professores que ministrassem as atividades físicas para os alunos de Educação Infantil fossem aqueles formados em licenciatura em Educação Física, ao contrário do observado nas duas prefeituras, onde as próprias professoras de sala é quem ministram as atividades de Educação Física.

\section{CONCLUSÃO}

Por meio do presente estudo foi possível concluir que a prática das brincadeiras folclóricas assume um papel de grande significado e importância para as crianças da pré-escola, visto que proporcionam a continuidade de práticas culturais, cheias de significados para os alunos, contribuindo para que estas não venham a ser esquecidas.

Segundo as professoras entrevistadas, as brincadeiras folclóricas influenciam positivamente no desenvolvimento dos aspectos afetivos e sociais, colaborando para a aquisição de atitudes e valores que nossa sociedade tanto carece, como cooperação, respeito mútuo e respeito às diferenças. Também proporcionam a socialização, interação e aproximação entre os alunos, assim como a construção e cumprimento das regras, o saber esperar sua vez, a expressão de sentimentos, a valorização de conquistas (auto-estima), o controle de impulsos e frustrações, e o aumento da autonomia.

Vimos, portanto, a necessidade de uma Educação Física Infantil que explore mais o que o aluno já conhece, suas experiências, as vivências de seu meio social, através das brincadeiras folclóricas, de forma a estar contribuindo com o processo de resgate cultural, para que a cultura tão vasta e rica de nosso país possa continuar viva.

Assim, respeitando os interesses e motivações dos alunos, o professor contribui para o desenvolvimento dos aspectos afetivos e sociais de maneira lúdica e prazerosa, proporcionando uma infância escolar feliz, que sem dúvida influenciará de forma positiva no futuro do aluno.

\section{REFERÊNCIAS}

ASSIS, M. C; ASSIS, O. Z. M. (Org.). Proepre - fundamentos teóricos da educação infantil. 5. ed. Campinas: Graf. FE: IDB, 2003.

BRASIL. Ministério da Educação e do Desporto. Professor da pré-escola. 4. ed. Brasília, 1995. v. 1. 
BRASIL. Ministério da Educação e do Desporto. Referencial curricular nacional de educação infantil: formação pessoal e social. Brasília: 1998a. v. 2.

BRASIL. Ministério da Educação e do Desporto. Referencial curricular nacional de educação infantil: conhecimento de mundo. Brasília: 1998b. v. 3,

DAOLIO, J. A cultura da educação física escolar. Revista Motriz, Rio Claro, v. 9, n. 1, supl., p. S 33-S 37, jan./ abr. 2003.

FREIRE, J. B. Educação de corpo inteiro: teoria e prática da educação física. 4. ed. São Paulo: Scipione, 1997.

GALLARDO, J. S. Delimitando os conteúdos da cultura corporal que correspondem a área de Educação Física. Conexões, Campinas, v. 1, n. 1, p. 39-54, 2003.

KRUEGER, M. F. A relevância da afetividade na educação infantil. Revista Leonardo Pós. Instituto Catarinense de Pós-Graduação, Santa Catarina, n. 3, ago./dez. 2003. Disponível em: $<$ http://www.icpg.com.br/hp/revista/index.php? rp_auto=3>. Acesso: 27 jun. 2006.

LIMA, E. C. A. S. A atividade da criança na idade pré-escolar. São Paulo: FDE, 1992. (Série Idéias)

PIAGET, J. Psicologia da inteligência. Rio de janeiro: Zahar, 1977.

RAMOS, M. C. A. Jogar e brincar: representando papéis, a criança constrói o próprio conhecimento e, conseqüentemente, sua própria personalidade. Revista Leonardo Pós. Instituto Catarinense de Pósgraduação. Santa Catarina, n. 1, jan./jun. 2002. Disponível em: $<$ http://www.icpg.com.br/hp/revista/index.php? rp_auto=1>. Acesso em: 27 jun. 2006.

SOLER, R. Educação Física escolar. Rio de Janeiro: Sprint, 2003. 


\section{Elise Helena de Morais Batista}

Anhanguera Educacional S.A

\section{Andréa Rodrigues de Amorim}

Anhanguera Educacional S.A

\section{Referência do artigo:}

\section{ABNT}

BATISTA, E. H. M., AMORIM, A. R. As brincadeiras folclóricas na educação física infantil: influências no desenvolvimento afetivo-social, v. 6, p. 628-639, 2008.

\section{APA}

Batista, E. H. M., \& Amorim, A. R. (2008) As brincadeiras folclóricas na educação física infantil: influências no desenvolvimento afetivo-social. Conexões, 6, 628-639.

\section{VANCOUVER}

Batista EHM, Amorim AR. As brincadeiras folclóricas na educação física infantil: influências no desenvolvimento afetivo-social. Conexões, 2008; 6: 628-639. 